\title{
Ovarian activity of female ring doves (Streptopelia risoria) exposed to marginal stimuli from males*
}

\author{
DEAN R. LAMBE $\dagger$ and CARL J. ERICKSON \\ Duke University, Durham, North Carolina 27706
}

\begin{abstract}
Although previous studies have indicated that male displays promote ovulation in the female ring dove, it was unknown whether perception of the male's structural features was an essential prerequisite for the response. In the present study, females were exposed to the shadow of a courting male or to his vocalization alone. Vocalization itself was ineffective in inducing ovulation, but half of the females provided with the additional visual stimulus laid eggs. It is suggested that perception of the feather and color patterns of the male are not essential conditions for the female's response.
\end{abstract}

In many avian species, the female exhibits ovulation and egg laying only in response to the presence of certain critical factors in the environment. For example, female budgerigars (Melopsitticus undulatus) lay eggs in response to the vocalizations of males (Vaugien, 1951). Even when females are isolated in a dark room, male vocalizations may be effective in producing the response. Brockway (1965) has shown that of the several vocal components performed by the male budgerigar, a single call (the "soft warble") is most effective in producing ovarian activity in the female. These studies demonstrate that species-specific social stimuli may elicit neuroendocrine as well as neuromuscular responses. In the ring dove (Streptopelia risoria), although male vocalization may produce increases in size and weight of the female's reproductive tract (Lehrman \& Friedman, 1969), ovulation and egg laying only rarely occur without visual access to a male. Moreover, Erickson and Lehrman (1964) have shown that it is male display rather than the mere presence of a male that results in gonadotropin secretion in the female. Recently, Erickson (1970) has suggested that nest soliciting, one of several components of the male repertoire, may be particularly effective in promoting the ovarian response.

These studies have underscored the essential role of social behavior in promoting the extensive endocrinological changes upon which the reproductive cycle is based, but it is possible that in doing so they have diverted attention from necessary predisposing factors. Although perception of the species-specific morphological characteristics of the male appears insufficient in itself to induce ovulation in the female ring dove (Erickson \& Lehrman, 1964; Erickson, 1970), identification of such characteristics may be a necessary prerequisite for her response. Dove species vary markedly in morphological as well as behavioral characteristics. Most striking are the variations in neck,

*This research was supported by the National Science Foundation through Research Grant GB-6641 and by the U.S. Public Health Service through Research Grant HD 04482.

$\nmid$ Requests for reprints should be sent to Dean R. Lambe, Psychology Department, Marietta College, Marietta, Ohio 45750. head, and wing markings that occur among closely related species (Goodwin, 1967). The purpose of the present study was to determine whether female ring doves would exhibit the characteristic hormonal responses when these structural characteristics of the stimulus males were obscured.

\section{METHOD}

\section{Subjects}

The Ss were 38 female ring doves drawn from the breeding colony of Duke University. Thirty-eight male ring doves served as stimulus animals.

All birds remained with their parents for 3 weeks after hatching. They were then banded for identification and transferred to a stock cage with 8-10 other squabs of similar age, and remained there until 5 months of age.

Housing and maintenance were as described by Morris and Erickson (1971). The lighting, which was clock-controlled, remained on from 0800 to $2200 \mathrm{~h}$.

\section{Apparatus}

Females had access to either the shadow of a courting male plus ring dove vocalizations or to vocalizations alone. This was accomplished with the apparatus depicted in Fig. 1. The female was confined to the end chamber, while the male resided in an adjacent compartment. A $35-\mathrm{mm}$ slide projector cast a shadow of the male on the partition separating these two chambers. In the condition in which females were exposed to the shadow of the male, the partition consisted of two layers. The surface nearest the female was of frosted translucent Plexiglas; that layer nearest the male was a semisilvered mirror. This arrangement allowed the female to see only the shadow of the male, while the male could see only his own reflection, an image which he courted avidly. When females were limited to vocalization alone, an opaque metal sheet was placed as a third layer between the Plexiglas and semisilvered mirror. In all conditions, a clear glass plate interposed between the male and the projector prevented the male from moving far from the partition. This ensured a sharp image approximating the size of the male. In addition, a pane of frosted Plexiglas closer to the projector reduced unnecessary glare.

Each of the animal compartments was provided with feed, water, and a nest bowl. In addition, the female's chamber contained pine needles as nest-building material.

In the shadow (S) condition, all lighting was provided by the $200-\mathrm{W}$ bulb of the slide projector. In the no-shadow (NS) 




Fig. 1. Apparatus for exposing females to the shadows of courting males.

treatment, illumination of the female's chamber was supplemented by an additional light source. This consisted of a 6-W incandescent fixture mounted in the ceiling of the chamber. Most of the light from this ceiling fixture was reflected from the Plexiglas partition. Through adjustments of a variable transformer connected to the slide projector, illumination of the female chamber in the $S$ condition was equated with that in the NS condition. Equality was confirmed with the aid of a Weston Model 748 Universal exposure meter. The lighting was clock-controlled and maintained on the same 14-h light schedule as the colony.

\section{Procedure}

Sixteen pairs of ring doves were assigned to the $S$ condition and 16 pairs to the NS condition. All birds in these conditions had been mated and had raised young in the colony; however, none of the animals was tested with a previous mate. Four sets of apparatus were available, and thus four pairs could be run simultaneously. Since all testing was performed in the same room, all Ss could hear, although not see, other Ss. There were eight replications, each consisting of two $S$ and two NS pairs. Each apparatus provided alternating $S$ and NS conditions on the successive replications. All Ss remained in the apparatus for 12 days. On the morning of Day 1 , the females were inserted first, followed by the males; the test cages were then illuminated.

Upon the completion of this portion of the experiment, six reproductively inexperienced adult females were tested. Each was exposed to the shadow of a courting male of age and experience comparable to that of males in the $S$ and NS groups.

\section{RESULTS}

Half of the females exposed to the shadow of a courting male laid two eggs while in the test apparatus. In contrast, none of the females in the NS group ovulated $(p<.01$; Fisher exact test $)$. Thus, the addition of a visual stimulus, although two-dimensional and achromatic, appears to enhance significantly the ovarian response of females. In fact, the first egg of all laying females appeared within 6 to 9 days after introduction to the test cages, a range of delay approximating that of females given normal exposure to males (see Martinez-Vargas \& Erickson, in press). It is of interest to note that in the $\mathrm{S}$ group there was a sharp discrepancy between the reproductive tracts of those females that laid eggs and those that failed to do so. The difference suggested that responsiveness was of an all-or-none nature. Typically, females kept in visual isolation in our colony have oviduct weights ranging from 0.2 to $0.8 \mathrm{~g}$ and ovarian follicles ranging from 1 to $5 \mathrm{~mm}$ in diam. As ovulation approaches after several days of exposure to a male, oviduct weights approximate $4.50 \mathrm{~g}$ and follicle diameters reach $16 \mathrm{~mm}$. In short, the few days prior to ovulation are marked by a dramatic increase in reproductive tract development. Figure 2 indicates the state of the reproductive tract on Day 12 in females of the three groups. The ordinate represents an ordinal scale of reproductive tract activity. Up to the point of first ovulation, increases in oviduct weight are monotonic and provide a good measure of tract development. Thus, oviduct weights are presented for those females that failed to achieve ovulation. The responses of ovulating females are simply represented by the number of eggs laid. All females in the NS group and all females that failed to lay eggs in the $\mathrm{S}$ group showed a complete failure of reproductive tract development. In fact, oviduct weight and follicle diameter appeared unusually small. It is unlikely that these differences were due to subtle variations in prior breeding experience, since inexperienced females exhibited a similar dichotomy in responsiveness when exposed to stimuli like those presented to the S-group females.

\section{DISCUSSION}

It is clear that visual perception of the male is an important factor in the induction of ovulation and egg 
laying in the female ring dove, but the present study also indicates that many females will respond when the visual stimulus is severely limited. Half of the tested females responded when the markings, color, feather patterns, and three-dimensionality of the males were obscured. It is somewhat surprising that such a large proportion of the shadow-exposed females ovulated when provided with such a limited visual stimulus. Egg laying represents a considerable physiological investment in female birds. It is generally thought that clear identification of the male as a conspecific must occur before the reproductive cycle will proceed (e.g., Sibley, 1957). However, it is also established that birds of many species hybridize freely when confined together in captivity, and doves of several species, including ring doves, have been crossbred in the laboratory (e.g., Lade \& Thorpe, 1964). This suggests that species-specific morphological characteristics may be primarily instrumental in attracting the animals to one another. Once proximity is established, either through confinement or mutual attraction, the endocrinological responses may follow under the influence of relatively unspecific social factors. However, one cannot overlook the possibility that in the ring dove years of domestication may have reduced the dependence of the neuroendocrine responses upon strict species identification.

In sharp contrast to the ovulating females, half of the females that had been similarly exposed showed no evidence of ovarian activity. This response seems to be all-or-none in character, since all responding animals laid

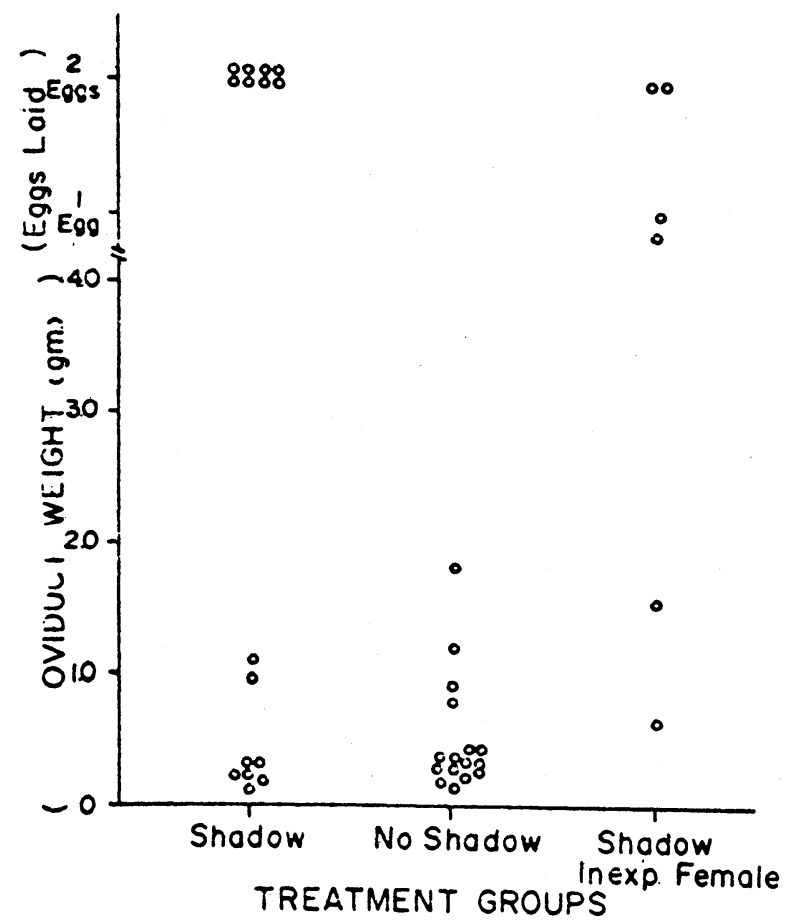

Fig. 2. Reproductive tract development and egg laying of individual female ring doves on the 12 th day in the test apparatus. their eggs within the first 9 days of the 12-day exposure period, a delay approximating that of females given full exposure to normal courting males. Such dichotomous responses are similar to those found by the junior author in another, as yet unpublished, study, where it was discovered that $42 \%$ of females given full contact with castrated, noncourting males would ovulate within 7 days, but the remaining $58 \%$ showed no ovarian activity. Taken together, these studies suggest that under marginal stimulus conditions, a combination of factors may or may not reach a threshold for gonadotropin secretion and consequent ovulation. Possibly, the contributing factors are many, and it may be that no single stimulus is necessary for the response to occur. The presence of nesting material (Lehrman, Brody, \& Wortis, 1961), vocalization (Lehrman \& Friedman, 1969), colony sounds (Lott \& Brody, 1966), and visual perception of a courting male (the present study) may all contribute in varying degree to the minimal requirements for the female's ovarian response.

\section{REFERENCES}

Brockway, B. F. Stimulation of ovarian development and egg-laying by male courtship vocalization in budgerigars (Melopsittacus undulatus). Animal Behaviour, 1965, 13, 575-578.

Erickson, C. J. Induction of ovarian activity in female ring doves by androgen treatment of castrated males. Journal of Comparative \& Physiological Psychology, 1970, 71, 210-215.

Erickson, C. J., \& Lehrman, D. S. Effect of castration of male ring doves upon ovarian activity of females. Journal of Comparative \& Physiological Psychology, 1964, 58, 164-166.

Goodwin, D. Pigeons and doves of the world. London: British Museum (Natural History), 1967.

Lade, B. I., \& Thorpe, W. H. Dove songs as innately coded patterns of specific behaviour. Nature, 1964, 202, 366-368.

Lehrman, D. S., Brody, P. N., \& Wortis, R. P. The presence of the mate and of nesting material as stimuli for the development of incubation behavior and for gonadotropin secretion in the ring dove (Streptopelia risoria). Endocrinology, 1961, 68, 507-516.

Lehrman, D. S., \& Friedman, M. Auditory stimulation of ovarian activity in the ring dove (Streptopelia risoria). Animal Behaviour, 1969, 17, 494-497.

Lott, D. F., \& Brody, P. N. Support of ovulation in the ring dove by auditory and visual stimuli. Journal of Comparative \& Physiological Psychology, 1966, 62, 311-313.

Martinez-Vargas, M. C., \& Erickson, C. J. Some social and hormonal determinants of nest-building behaviour in the ring dove (Streptopelia risoria). Behaviour, in press.

Morris, R. L.. \& Erickson. C. J. Pair bond maintenance in the ring dove (Streptopelia risoria). Animal Behaviour, 1971, 19. 398-406.

Sibley, C. G. The evolutionary and taxonomic significance of sexual dimorphism and hybridization in birds. Condor, 1957. 59, 166-191.

Vaugien, L. Ponte induite chez la perruche ondulée maintenue à l'obscurité et dans l'ambiance des volières. Compte. Rendu de l'A cadémie des Sciences, Paris, 1951, 232, 1706-1708.

(Received for publication February 13, 1973; revision received April 24, 1973: accepted May 10, 1973.) 